\title{
Planning for Success: Factors influencing change in teacher education
}

Jo-Anne Ferreira, Griffith University

Lisa Ryan, University of the Sunshine Coast

Daniella Tilbury, Macquarie University

\begin{abstract}
Teacher education is widely recognized as a key strategy that is yet to be effectively utilized to embed environmental education and/or education for sustainability in schools. This paper reports on a research study that examined a range of pre-service teacher education initiatives, both in Australia and internationally, that were seeking to reorient teacher education towards environmental sustainability. This paper reports on six factors utilized across the initiatives that were critical to their success. These were (1) the nature and length of funding arrangements; (2) the range and quality of partnerships and networks; (3) the curriculum focus and the teaching and learning processes used; (4) the nature of, and incentives for, participant engagement; (5) the level at which a change was being sought; and (6) the use of evaluation as a tool for learning and ongoing improvement. This paper discusses why and how each of these six factors proved critical and explores the implications for initiatives seeking to reorient teacher education towards environmental sustainability.
\end{abstract}

Keywords: education for sustainability, teacher education, systemic change, reorienting teacher education, higher education, critical success factors

Jo-Anne Ferreira is Convenor of the Master of Environmental Education program at Griffith University, Brisbane, Australia; Lisa Ryan teaches in sustainability education in the Faculty of Science, Health and Education at the University of the Sunshine Coast, Maroochydore, Australia; and Daniella Tilbury is Director of the Australian Research Institute in Education for Sustainability (ARIES), Macquarie University, Sydney, Australia. 
There have been, since the Tbilisi intergovernmental conference on environmental education (UNESCO-UNEP 1978), a range of initiatives that have sought to embed or mainstream $^{\mathrm{i}}$ environmental education and education for sustainability ${ }^{\mathrm{ii}}$ in teacher education, both in Australia and internationally (UNESCO-UNEP 1990; UNESCO 2005a; UNITWIN/UNESCO 2000). These initiatives have been influenced by the belief that there is a need to reorient teacher education towards sustainability because institutions of teacher education fulfil vital roles in the global education community; [and] they have the potential to bring changes within educational systems that will shape the knowledge and skills of future generations. Often education is described as the great hope for creating a more sustainable future; teacher education institutions serve as key change agents in transforming education and society so that such a future is possible. (UNESCO 2005a, p. 6)

Unfortunately, despite the claimed importance of the role of teacher education, there has been, to date, no teacher education initiative in Australia that has strategically set out to mainstream environmental or sustainability issues into the core offerings of all pre-service teacher education programmes. While there have been some teacher education initiatives in the area of environment or sustainability, such as the UNESCO Reorienting Teacher Education towards Sustainability initiative (UNESCO 2005a) and the UNESCO and Griffith University Teaching and Learning for a Sustainable Future project (UNESCO 2005b), these have not resulted in a broad-scale inclusion of environmental and sustainability concerns in pre-service teacher education in Australia (Tilbury, Coleman and Garlick 2005).

In seeking to understand why this might be the case, we undertook a review of the key design features and implementation strategies (what we termed 'models of professional development') of over 20 initiatives seeking to include environmental education and/or education for sustainability in pre-service teacher education both in Australia and internationally. These initiatives included: the European Union (EU) funded Sustainability Education in European Primary Schools (SEEPS) project (www.education.ed.ac.uk/esf/project-info/index.html); the University of Greenwich's Teaching and Learning at the Environment, Science and Society Interface (TaLESSI) project (www.gre.ac.uk/ bj61/talessi); UNESCO’s Teaching and Learning for a Sustainable Future (TLSF) project (www.unesco.org/education/tlsf/); the joint UNESCO-ACEID and Griffith University Learning for a Sustainable Environment 
(LSE) project (http://www.ens.gu.edu.au/ciree/LSE/INDEX.HTML); Macquarie University’s Action-Research for Change Towards Sustainability (ACTS) project (http://www.environment.gov.au/education/publications/pubs/acts.pdf) ; the University of Wales at Bangor's Embedding Global Citizenship and Sustainable Development in Initial Teacher Education and Training (EGCSD) project (http://www.bangor.ac.uk/addysgbyd/); and Jamaica’s Sustainable Teacher Environmental Education Project (STEEP) (http://www.enact.org.jm/Publications/Pulbications 5000.htm).

The research was undertaken through a systematic review of relevant project literature, including journals, theses, evaluations, initiative websites and other project documentation. Correspondence also took place with initiative leaders in order to source further information and validate our appraisals. The research did not collect empirical data, but instead reviewed program documentation in an effort to identify the strategies for change underpinning each initiative.

An interpretive descriptive approach using the constant comparative method of data analysis was employed to analyse the data collected. According to Maykut and Moorhouse (1994), interpretive-descriptive research is exploratory and reliant on words and meanings. Our analysis was thus undertaken using an iterative process in which the data was read and re-read to determine recurring themes and approaches. In particular, our examination of the documents and discussions with initiative leaders sought to identify the philosophy of change driving the development and implementation of the initiative. The researchers then discussed potential themes and approaches until agreement was reached.

It is also important to note that this research did not represent an exhaustive study of all teacher education for sustainability initiatives but instead captures a range of efforts. The study was also limited to easily accessible English-language documents and by a short timeframe of six months.

The seven initiatives named above provide a good snapshot of the various models of professional development we identified in the 20 initiatives we reviewed. The particular contexts and geographical locations of these seven initiatives are broad and 
varied. For example, some, such as UNESCO's TLSF project and the European Union's (EU) SEEPS project, were broad in target and range, with the UNESCO project having an international reach, and the EU project being Europe-wide. Others, such as the Macquarie University based ACTS project, or the Jamaican STEEP project, only targeted one or a few institutions, within one country, or one city. While the initiatives differed in their philosophies, approaches, methods, and contexts, we were none-the-less able to identify three broad models of professional development or approaches to change underpinning this diverse range of initiatives. We named these the:

- Collaborative Resource Development and Adaptation model: This model seeks to bring about change through the development and adaptation of high quality curriculum and pedagogy resources. It does not usually seek to bring about change across a whole teacher education system;

- Action Research model: This model aims to build capacity by engaging the initiative participants in a ‘deep' process of reflective action. This model thus targets change at the practitioner and institutional level; and

- Whole-of-System model: This is a radically different model from the other two in that it seeks change in a multi-faceted and system-wide manner.

A detailed analysis of each of these models can be found in Ferreira, Ryan and Tilbury (2007).

The purpose of this paper is not to provide an analysis of these models but rather to examine the factors that our research found greatly enhanced the impact or success of these models in influencing and embedding change in teacher education. Broadly, the success or otherwise of these models related to:

- the nature and length of funding and management arrangements;

- the range and quality of partnerships and networks;

- the curriculum focus and teaching and learning processes used;

- the nature of, and incentives for, participant engagement;

- the level at which a change was being sought; and

- the use of evaluation as a tool for learning and on-going improvement. 
This paper focuses on describing these six critical success factors and discusses their contribution to the success of the initiatives we reviewed in bringing about change in teacher education. It is hoped that such a discussion will inform the future development of initiatives seeking to mainstream environmental and sustainability concerns in pre-service teacher education.

\section{Funding and leadership}

Pre-service teacher educators developed almost all the initiatives we reviewed. However, most initiatives were reliant on funding external to the institution for their execution. Our study found that funding cycles and levels of autonomy exercised at the project management level were important variables influencing an initiative's level of success and longevity. For example, none of the seven initiatives referred to above operated fully beyond their funding cycles. This does not imply that the initiatives were unsuccessful or ineffective. Indeed, the resource materials and outcomes of these initiatives, such as those of the LSE project, for example, continued to influence curricula in some institutions beyond the life of the initiative (Fien, Kumar and Ravindranath 2001). However, an inability to financially continue to support initiatives was a major obstacle to the longevity of initiatives, as was evidenced in the TaLESSI project for example, which struggled to maintain momentum when funding was no longer available. We thus argue that longer and more secure funding cycles will provide greater opportunities for change to become embedded, as participants can focus on the project rather than on investigating additional funding sources. In addition, longer and more secure funding cycles, of at least two to five years, will also allow for project evaluations to contribute to the meaningful refinement of initiatives.

\section{Partnerships and networks}

Partnerships are increasingly recognised as an important component in achieving sustainability (UNCED 1992; UNESCO 2002; Tilbury, Podger and Reid 2004), with UNESCO arguing that 'partnering and networking has proven successful in sharing examples and lessons of good practice and encouraging adoption by others' (2002, p. 39). Indeed, our review found that all the initiatives placed high importance on partnerships which were sought with a variety of sectors including NGOs, intergovernmental bodies, other teacher education institutions (both nationally and 
internationally), resource centres, other faculties within the university, industry bodies, and boards of teacher education, for example. There were many motivations for forming partnerships identified by the initiatives that were investigated, such as:

- $\quad$ sharing expertise;

- capitalising on funding opportunities;

- $\quad$ ensuring relevance to market demands from industry and employers;

- maximising the multiplier effect by networking across institutions; and

- providing mutual peer support and encouragement.

Although each partnership arrangement varied, it would appear that many benefits arose out of these relationships. Some of the initiatives we reviewed, such as TLSF, for example, developed highly effective partnerships with prestigious and influential organizations like UNESCO (UNESCO 2005b),. Such partnerships provided many opportunities for international endorsement, recognition and broad-scale dissemination. We found that these kinds of prestigious partnerships also helped to garner support for an initiative both inside the university and more generally across an entire teacher education system. For example, in the case of TLSF, UNESCO distributed regional specific adaptations (in several languages) and endorsed the resource to every ministry of education (Matsuura 2002). We assert, therefore, that partnerships with influential organizations such as intergovernmental bodies and international NGOs can confer prestige and importance to initiatives seeking to embed environmental education and/or education for sustainability in pre-service teacher education. In addition, such organizations can also influence the potential outreach and adoption of new initiatives beyond the original site as these organizations often have large multi-sectorial memberships and operate across country borders (Tilbury, Goldstein and Ryan 2003).

Some of the initiatives reviewed also formed partnerships with organizations where a member from the partner organization worked for a period of time within an institution, to support the work of participants directly. This was the case in the University of Wales at Bangor's EGCSD project, for example. We found that such partnerships provided opportunities for sharing of expertise as well as the load associated with implementing a new initiative. This allowed for the contribution and cross-fertilisation of new ideas and strategies across organizations. 
Most commonly, partnerships were established to develop supportive professional networks. In the LSE project, for example, teacher educators from across the AsiaPacific, often working in isolation not only in their respective institutions, but also in their country, found the support offered by 'critical friends' in the LSE network invaluable (Fien and Maclean 2000). In all initiatives reviewed, such networks proved extremely important in building a strong support base for teacher educators who were often working outside their comfort zones with new approaches, technologies and/or ideas. While networking partnerships can exist within an institution, in the initiatives we reviewed, they were most frequently used to connect members from different institutions, where teacher educators were often working in isolation.

Some initiatives also sought to build partnerships with stakeholders across the teacher-education system, to influence change across the whole system. This was the case with the Jamaican STEEP project, were partnerships were fostered with the teacher registration authority, the National Environmental Education Council, teacher education institutions, ministries of environment and education, and a range of environmental NGOs (Collins-Figueroa, M. personal communication, 2005). In our review, we found that such system-wide partnerships increased stability and synergies because the aims and objectives of an initiative were mirrored at all levels within a teacher education system, from policy to practice.

Such networks of partners can provide mutual peer support, advice and information, a sense of being part of a community of inquiry, and provide exemplars of practice from other members. Several of the initiatives we reviewed, such as the University of Greenwich's TaLESSI project, the University of Wales at Bangor's EGCSD project, and Jamaica's STEEP project, negotiated partnerships across disciplinary boundaries. This meant, for example, in the case of the TaLESSI project, that the attempts of the academic staff from the Environmental Science faculty to integrate the disciplinary perspectives of the natural sciences (for example, biology and chemistry) with the social sciences (for example, economics and sociology) and humanities (notably ethics and philosophy) necessitated the fostering of cross-disciplinary partnerships (Jones and Merrit 1999). The networks we examined were facilitated by regular meetings, seminars, and through email. These networks involved all participants, and 
utilised a participatory approach that produced an atmosphere of cooperation. Indeed, it appears from our review that the more equal and participatory the partnership, the better the shared process and outcomes for an initiative's participants.

\section{Program focus and pedagogical principles}

Recent education for sustainability literature advocates holistic integrated concepts of sustainability that include the social, economic, political, cultural and ecological dimensions of the environment and sustainability, along with teaching and learning pedagogies that are process-oriented and seek to develop critical thinking skills and actively engage learners (Tilbury et al. 2005). Robottom (1987) also argues that teacher professional development should be enquiry-based, participatory, community and action-based, collaborative, and reflective in practice. The most successful, widespread and long-lasting initiatives we reviewed were those that reflected environmental education and/or education for sustainability 'best practice' in both program focus and pedagogy.

Of the initiatives we reviewed, those that were interdisciplinary, rather than singleissue or single-discipline focussed, has success in embedding change because deeper and more complex understandings of sustainability were negotiated and constructed across often-conflicting disciplines. For example, the whole focus of the TaLESSI project was on fostering interdisciplinarity (Jones and Merritt 1999), which was, however, not easily cultivated, particularly in traditional educational institutions where disciplinary boundaries are so well established. Of those initiatives that did manage this change, three different approaches to facilitating interdisciplinarity were taken:

1. In the EGCSD project, a central coordinator was appointed who liaised with all academics, assisting them in infusing environmental education and/or education for sustainability into their faculty by making connections with initiatives/ strategies that academics in other institutions were already implementing (Bennell 2004);

2. Jamaica's STEEP initiative organised theme days, such as Wetlands Day, which provided teacher education staff with discrete and easy to implement interdisciplinary topics. The theme days also provided opportunities for 
environmental NGO staff to assist with technical information and teaching activities (Collins-Figueroa, personal communication 2005); and

3. In the Greenwich University TaLESSI project, staff meetings and planning sessions enabled a group of academics to investigate opportunities for interdisciplinary and cross-disciplinary approaches in their teaching (Jones and Merrit 1999).

The initiatives reviewed all showed evidence of having engaged with the most current, cutting-edge understandings of, and knowledge about, sustainability at the time of their development. For example, the SEEPS project developed a teacher education resource that supports a whole-school approach to sustainability. The resource goes beyond the mere inclusion of sustainability into the curriculum, by also including modules on leading and managing change, encouraging student participation and monitoring and evaluation (Shallcross 2004).

Another factor critical to the success of the initiatives reviewed was the congruence between the teaching and learning processes promoted and the principles of environmental education and/or education for sustainability. These principles call for the development of:

- critical, creative and futures thinking skills to develop alternative and innovative solutions to sustainability issues;

- needs assessment and action-oriented skills to motivate, manage and measure change towards sustainability;

- interpersonal and intercultural skills in order to redefine relationships amongst the various stakeholders;

- confidence and skills to deal with uncertainty;

- learning through engaging with real and specific problems or tasks; and

- learning about and for sustainability (Tilbury, Podger and Reid 2004, p. 7).

Teaching and learning within, and promoted by, nearly all initiatives was, therefore, not didactic but interactive and inquiry-based, engaging participants actively in the process of teaching and learning. These initiatives demonstrated a range of complementary approaches such as inquiry learning, experiential learning, problem solving, story telling, and reflection in action. They sought not only to introduce a range of new teaching and learning strategies to teacher educators but also provided opportunities for teacher educators to reflect on how they might use such approaches 
in their own teaching. For example, Griffith University's LSE project worked with a group of teacher educators to produce a professional development resource and in the process built skills and capacities in these strategies (Fien and Maclean 2000).

Successful initiatives also managed to leverage top-down support by linking their aims and objectives to broader institutional graduate or generic skills goals. Indeed, such a focus also helped to encourage interdisciplinarity, as generic skills such as problem-solving, working co-operatively, and taking action are increasingly advocated not only by environmental education but by other disciplines as well. Focussing on generic skills thus also provides an opportunity for all teacher educators to see the relevance of sustainability concerns to their discipline. An example of this is the Macquarie University ACTS project, which built sustainability into an identified need by industry for graduates to have confidence in dealing with uncertainty (Tilbury, Podger and Reid 2004).

\section{Nature of participant engagement}

Most initiatives reviewed seemed to make a choice between the depth at which participants would be able to engage, and the breadth or outreach of the initiative. For example, some initiatives, such as TLSF (UNESCO 2005) and SEEPS (Shallcross 2004), targeted a large (regional or international) audience, mainly through the dissemination of a resource through an online medium, while other initiatives, such as LSE (Fein, Heck and Ferreira 1997) and ACTs (Tilbury, Podger and Reid 2004), sought to engage a small audience intensely, thereby achieving small-scale but often longer lasting change, as opposed to broad change. While reaching a broader audience might appear most preferable, the experiences of both the LSE and ACTS initiatives illustrates that deep engagement by a small group of participants has the capacity to bring about long-term, sustainable and systemic change. In both these instances, for example, the network of support and action-research process developed during the funded period persisted after the funding was exhausted, and with the case of the ACTS initiative, well after the completion of the project (Tilbury Podger and Reid 2004). With a deep level of engagement over a longer period of time it appears participants are more likely to remain committed and to continue to seek ways in which to mainstream environmental education and/or education for sustainability ideas and approaches in their own teaching, and in the teaching of their colleagues. 
Simply engaging participants at a deep level does not ensure success, however. Ongoing support - from funding bodies, institutions and peer networks - is also needed in order to sustain the change. It may well be that offering long-term support to a group that has already engaged deeply with environmental education issues is an effective use of resources because the group is already 'tuned-into' such approaches. Providing such support may, however, require a changed approach to funding arrangements, as has been discussed earlier.

Using incentives to attract potential participants to the initiative was another factor critical to success. Interestingly, in the initiatives we reviewed, such incentives were seldom financial, with people willing to engage with an initiative for a range of alternative reasons. One of the most significant incentives we identified was the opportunity to be part of an initiative that was deemed to be valuable and worthwhile, by participants themselves, by institutional managers, and/or by reputable government, non-government and international agencies (such as UNESCO, government departments of education, national councils or committees, and prestigious NGOs). For example, evaluations from the LSE project explicitly indicated this:

Network members also commented on the positive support they had received from their colleagues and work related institutions. This came variously in the form of encouragement, assistance with secretarial support, photocopying, etc., and in the influence they were able to exert on existing courses and subject content. The credibility they gained from working on a well-known UNESCO project was seen as very influential in obtaining such support. (Fien, Kumar and Ravindrinath 2001; 218)

Such recognition seemed to provide teacher educators with a new sense of credibility, prestige and professional respect within their own institutions, especially when they had been chosen to be part of a nationally- or internationally-funded initiative. This points to high-level recognition and support acting as a motivating factor in participants' decision to engage with an initiative.

In addition, many initiatives provided opportunities for networking with colleagues within and outside of their institutions (sometimes internationally); and for networking in new and more direct ways with university executives, high-level 
ministry officials, councillors on national bodies and industry partners. Providing opportunities for developing new professional networks gave participants' access to a whole range of new knowledge and experiences; opportunities for engaging in highlevel decision-making; opportunities for travel (both domestic and international); for access to research funding; and new opportunities for research and publication. For example, in the University of Wales at Bangor's EGCSD project, academic staff had the opportunity to spend time working overseas, while in the Jamaican STEEP project, participants had the opportunity to engage in high-level decision-making with government ministry officials and the National Environmental Education Council. Such incentives also allowed participants to feel supported within their institutions by their colleagues, their departments or faculties and their university executives; and to feel supported outside their institutions by government ministers, government departments, colleagues in other institutions, and professional associations and NGOs.

'Time-out' from the rigours of teaching to deeply consider and reflect on teaching practice was another significant incentive to involvement in some of the initiatives we reviewed. Recognition by institutions that participants were engaging in meaningful professional development also acted as an incentive. This recognition ranged from institutional support through providing leave, to the award of certificates and trophies (Fien, Kumar and Ravindrinath 2001).

Based on our examination of a range of initiatives, we thus argue that engaging participants at a 'deep' level over a prolonged period of time, along with recognition for and rewarding of engagement, seem to be critical to the success of initiatives seeking to mainstream sustainability in teacher education.

\section{Levels of intervention and approach to change}

Teacher education institutions do not exist in a vacuum but are shaped by the many contextual influences around them. Government policies and practices, professional standards for teachers, current curriculum documents, professional associations, and research all shape the way teacher education institutions are managed. Our study found that the initiatives that were most successful, that is the most effective in leveraging long-term and broad-scale change, were those that showed a complex understanding of this context and sought broad-scale, systemic change - through 
taking a multi-faceted and systematic approach to such change. Such an approach focuses on:

- the development of enabling policies;

- developing capacity amongst teacher educators, student teachers, administrative and ancillary staff; and

- co-ordinated professional development programs that facilitated the cascading of new ideas and practices throughout a system (Thomas 2004).

Unfortunately, only one of the initiatives we reviewed sought to bring about change in such a multi-faceted and system-wide way: Jamaica's STEEP project. The STEEP project negotiated partnerships at a variety of levels within the teacher education system to leverage top level endorsement - enabling a supportive political climate for the project - whilst also building the capacity of academic, administrative and ancillary staff to prioritise sustainability within their institutions. (Collins-Figueroa, 2005, pers. comm.; http://www.enact.org.jm/Publications/Pulbications 5000.htm)

Such an approach is complex, having to take all stakeholders within a system into account. It is not just about educating the educators, but also the decision-makers, policy developers, and curriculum writers. Perhaps this is why systemic and organisational change issues seem for the large part to be ignored by creators of professional development initiatives in environmental education and/or education for sustainability. However, if education for sustainability or any other educational perspective is to be mainstreamed in pre-service teacher education then issues of system-wide change need to be seriously addressed in the design and implementation of initiatives. Change needs to be planned for and targeted from both the top down and the bottom up, to ensure that the policies of the teacher education system are consistent with the practices of the teacher education system.

\section{Evaluation}

In general, evaluation of the initiatives we reviewed was poorly conducted, if at all. For example, no long-term evaluations were undertaken to indicate the sustainability and longevity of an initiative's impacts in any of the initiatives we examined. Only the two initiatives underpinned by the Action Research model, the LSE and ACTS initiatives, undertook well-structured, effective evaluations. This is because the action 
research model has evaluation 'built-in', which provides an opportunity for reflection and consideration to be given to evaluation findings, and allows for further rethinking and refining as part of the process (Altrichter, Kemmis, McTaggart, Zuber-Skerritt 2002; Kemmis 2006). However, even the LSE and ACTS evaluations were only indicative of the first cycle of action. Of the remaining initiatives, evaluations were most often undertaken to fulfil the requirements of funding bodies, not to improve the initiatives per se.

Such poor attention to evaluation may be linked to short-term funding cycles, which currently rarely acknowledge the need to refine and re-implement projects. Evaluation that occurs only at the end of the first cycle may suit the reporting requirements of funding bodies but does little to improve the quality or longevity of such programs. We thus argue that longer funding cycles are needed to allow for evaluations to be meaningfully used to refine and improve initiatives. Short-term funding cycles do not encourage the use of evaluation in this way.

\section{Conclusion}

In conclusion, our study found that there was a range of factors that were critical to the success of initiatives we reviewed. It is our contention that the success of initiatives seeking to mainstream sustainability in pre-service teacher education will be vastly improved if both initiative developers and leaders, and funding agencies, attend to these six factors - preferably simultaneously - during the development of pre-service teacher education initiatives. It is anticipated that this will not only improve the breadth and depth of such initiatives but also the longevity of the changes that are possible through such efforts to mainstream not only environmental education and education for sustainability but also other perspectives in pre-service teacher education. Attention to such factors may assist in pre-service teacher education being more effectively utilised to embed environmental education and/or education for sustainability in schools. 


\section{References}

Altrichter, H., Kemmis, S., McTaggart, R., Zuber-Skerritt, O. (2002). The concept of action research. The Learning Organization: An International Journal, 9 (3), 125131.

Bennell, S. (2004). Embedding Education for Global Citizenship and Sustainable Development (EGCSD) in Initial Teacher Education and Training Courses: Final report. Bangor: World Education Centre, University of Wales.

Ferreira, J., Ryan, L. and Tilbury, D. (2006). Whole School Approaches to Sustainability: A review of models for professional development in pre-service teacher education. Canberra: Australian Government Department of the Environment and Heritage and the Australian Research Institute in Education for Sustainability.

Ferreira, J., Ryan, L. and Tilbury, D. (2007). Mainstreaming Education for Sustainability in Initial Teacher Education in Australia: A review of existing professional development models, Journal of Education for Teaching, 33 (2), 225239.

Fien, J., Heck, D., and Ferreira, J. (eds.) (1997). Learning for a Sustainable Environment: A Professional Development Guide for Teacher educators, UNESCO Asia - Pacific Centre of Educational Innovation for Development and Griffith University. Available at: http://www.ens.gu.edu.au/ciree/LSE/main.htm [Accessed 27 April 2006].

Fien, J., Kumar, P. and Ravindranath M.J. (2001). An Action Research Network as a Strategy for Educational Change: The Learning for a Sustainable Environment Project'. Journal of Educational Change 2 (3), 207 - 221.

Fien, J. and Maclean, R. (2000). Teacher Education for Sustainability II. Two Teacher Education Projects from Asia and the Pacific. Journal of Science Education and Technology 9 (1), 37 - 48.

Hopkins, C., Damlamian, J., \& Lopez Ospina, G. (1996). Evolving towards education for sustainable development: An international perspective. Nature and Resources, 32 (3), 2-11.

Jickling, B. (2006). The Decade of Education for Sustainable Development: A useful platform or an annoying distraction? A Canadian perspective. Australian Journal of Environmental Education 22 (1), 99-104.

Jones P. and Merritt J. (1999). JGHE Symposium: The TALESSI Project: promoting active learning for interdisciplinarity, values awareness and critical thinking in environmental higher education. Journal of Geography in Higher Education 23 (3), $335-348$.

Kemmis, S. (2006). Participatory action research and the public sphere. Educational Action Research. 14 (4), 459-476. 
Manchester Metropolitan University (2001). Sustainability Education in European Schools, Socrates Programme Transnational Cooperation Projects. Unpublished Final Report.

Matsuura, K (22 Sept 2002) [address] Presented at the World Summit on Sustainable Development launch of the South African version of 'Teaching and Learning for a Sustainable Future' [Transcript] Retrieved October 05, 2007, from http://portal.unesco.org/en/ev.php-

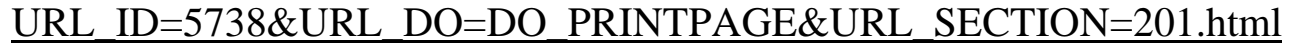

Maykut, P. and Moorhouse, R. (1994). Beginning qualitative research: A philosophic and practical guide. London: The Falmer Press.

National Environmental Education Council (NEEC), Jamaica (1998.) National Environmental Education Action Plan for Sustainable Development. Available at: http://www.nepa.gov.jm/neecweb/actionplan/planbook/tableofcontents.htm [Accessed 10 May 2006].

Scott, W. and Gough, S. (2003). Sustainable development and learning: Framing the issues. London: Routledge Falmer.

Shallcross, T. (ed.) (2004). School Development through Whole School Approaches to Sustainability Education: The SEEPS (Sustainable Education in European Primary Schools) project. Manchester: Manchester Metropolitan University.

Thomas, I. (2004). Sustainability in tertiary curricula: what is stopping it happening? International Journal of Sustainability in Higher Education. 5 (1), 33-47.

Tilbury, D., Coleman, V. and Garlick, D. (2005). A National Review of Environmental Education and its Contribution to Sustainability in Australia: School Education, Canberra: Australian Government Department of Environment and Heritage and Australian Research Institute in Education for Sustainability (ARIES).

Tilbury, D., Goldstein, W., Ryan, L. (2003). Towards Environmental Education for Sustainable Development: The contributions of NGOs in the Asia-Pacific Region, International Review for Environmental Strategies. 4 (1), 59-73.

Tilbury, D., Podger, P. and Reid, A. (2004). Action research for Change Towards Sustainability: Change in Curricula and Graduate Skills Towards Sustainability, Canberra: Australian Government Department of the Environment and Heritage and the Australian Research Institute in Education for Sustainability.

United Nations Conference on Environment and Development (UNCED) (1992). Chapter 36: Promoting education, public awareness and training, in UNCED Agenda 21: Programme of Action for Sustainable Development. Paris: UNCED.

UNESCO (2002). Education for Sustainability: From Rio to Johannesburg: Lessons learnt from a decade of commitment, Report prepared for UNESCO as Task Manager for Chapter 36 of Agenda 21. Paris: UNESCO. 
UNESCO (2005a). Guidelines and Recommendations for Reorienting Teacher Education to Address Sustainability, UNESCO Education for Sustainable Development in Action, Technical Paper No. 2, (Prepared by UNITWIN/UNESCO Chair on Reorienting Teacher Education to Address Sustainability [Charles Hopkins, Chair and Rosalyn McKeown, Secretariat] and the International Network of TeacherEducation Institutions). Paris: UNESCO.

UNESCO (2005b). Teaching and Learning for a Sustainable Future, Available at: http://www.unesco.org/education/tlsf/ [Accessed 6 August 2005].

UNESCO-UNEP (1978). The Tbilisi Declaration, Connect Vol. III, No. 1, pp. 1-8.

UNESCO-UNEP (1990). Environmentally Educated Teachers: The priority of priorities, Connect Vol. XV, No. 1, pp. 1-3.

UNITWIN/UNESCO (2000). Reorienting Teacher Education to Address Sustainability, Available at: http://www.edu.yorku.ca/?DocNum=resProj\&CurrInclude=resProj/UNITWINUNES CO.cfm [Accessed 24 May 2005].

\footnotetext{
${ }^{\mathrm{i}}$ Mainstreaming here refers to the inclusion of environmental education and/or education for sustainability in pre-service teacher education to such an extent that it becomes part of its core focus and activity. Mainstreaming goes beyond the addition of sustainability into the curriculum, implying instead the broad-scale adoption of a new idea across an entire system.

ii While there is debate within the field about the shift from 'environmental education' to ‘education/learning for sustainability’ (see, for example, Hopkins et al. 1996; Scott and Gough 2003; Jickling 2006), this paper uses both terms as some of the initiatives we reviewed refer to environmental education, while others refer to learning for or education for sustainability, usually depending on the time of the initiative's appearance.
} 